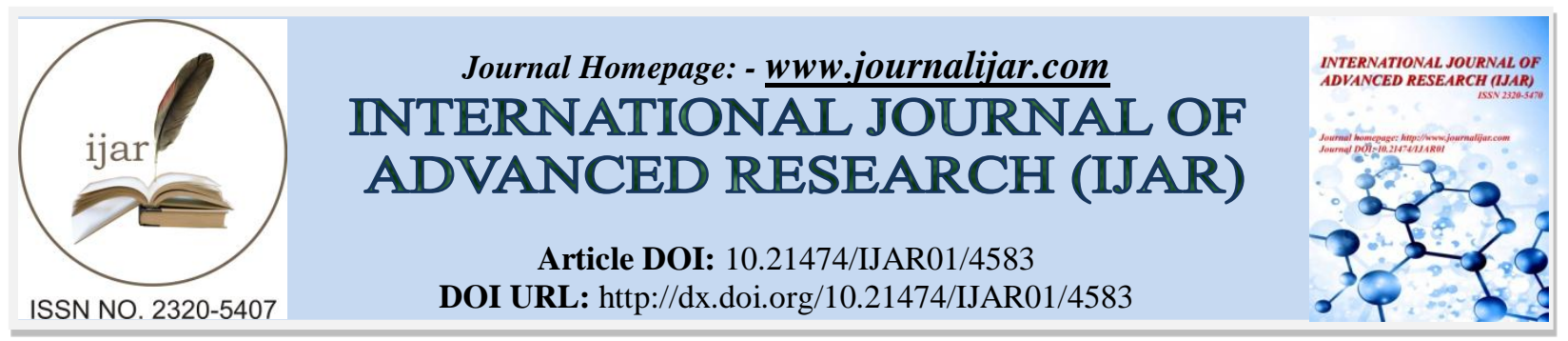

RESEARCH ARTICLE

\title{
A STUDY TO DETERMINE THE ASSOCIATION OF BODY MASS INDEX WITH BALANCE AND MOBILITY MEASURES IN COLLEGE GIRLS.
}

*Jothi Prasanna. $K^{1}$, Kajal Sahana. ${ }^{2}$ and Sivakumar. V. P. $\mathbf{R}^{3}$.

1. Assistant Professor, SRM college of Physiotherapy, SRM university.

2. Student, SRM college of Physiotherapy, SRM university.

3. Dean, SRM college of Physiotherapy, SRM university.

\section{Manuscript Info}

Manuscript History

Received: 23 April 2017

Final Accepted: 25 May 2017

Published: June 2017

Key words:-

Body Mass Index ,Flamingo balance test, Timed UP and Go test.

\section{Abstract}

Objective: The increased prevalence of obesity in adults is especially concerning given the association between obesity and impaired physical function. Overall , $13 \%$ of world's adult population (11\% of men and $15 \%$ of women ) were obese in 2014.Globally the prevalence of obesity in women exceeds than men. Physical function refers to a person's ability to perform basic and instrumental activities of daily living and mobility tasks. So, Impairments in physical function, such as the components of mobility and balance, have been linked to the development of disability. Measurements of body mass index is relatively simple and easier to calculate.so, considering the factor were comparing the Body Mass Index with balance and mobility measures To find association of Body Mass Index with balance and mobility measures in college girls.

Methods: Non-experimental design, Observational type. 300 subjects were selected and segregated into 3 groups based on their Body Mass Index, balance and mobility were assessed using flamingo balance test and timed up and go test. Flamingo balance test and Timed Up and Go test (TUG)

Results: Statistical analysis was done. The underweight and overweight subjects show more difference in the balance test compared with the mobility test conducted $(\mathrm{p}<0.05)$.

Conclusion: This study concludes that there is a correlation between balance and Body Mass Index for underweight and overweight individuals, and also concludes that there is no correlation between Balance and Body Mass Index for normal subjects .This study also concludes mobility and Body Mass Index in underweight, normal, and overweight Individuals.

Copy Right, IJAR, 2017,. All rights reserved.

\section{Introduction:-}

Anthropometric measurements are simple and widely used diagnostic tool for determining human development ,maturation and wellness(WHO,1995). Body Mass Index, Body Mass Index indicates how much an individual's body weight conforms or departs from what is normal ,healthy or desirable for person of specific height.[26] 
Body weights are generally classified into underweight, normal, overweight and obese using WHO cut-offs(WHO 1995).[13] Underweight, overweight and obese have been linked to several morbidities and mortality and are therefore considered as abnormal or unhealthy body weight. Obesity and underweight are extremes of body weight abnormalities.

Obesity is associated with serious medical complications that impair quality of life. It also modifies body geometry, increases the mass of the different segments, and imposes functional limitations pertaining to the biomechanics of activities of daily living that may predispose the obese to injury.[7]. One of these limitations relates to balance control. Proper balance control is a critical factor in terms of fall prevention because balance impairments have been identified as important risk factors for falling.

Overweight causes physical discomfort ,psychological trauma and predisposes the individual to a complex health condition termed metabolic syndromes characterized by diabetes, lipid disorder.[9]

Underweight on other hand,is associated with malnutrition, anaemiaand infectious disease such as malaria,pneumonia and HIV/AIDS and death(WHO-1995). Underweight patients often lack sufficient nutritional reserves to draw from during ill health and hence, are at higher risk of mortality.

Overweight and obesity results from an energy imbalance. The body needs a certain amount of energy (calories) from food to keep up basic life functions. Body weight tends to remains the same when the number of calories eatens equals the number of calories the body uses or burns. Overtime when people eat and drink more calories than they burn the energy balance tips towards weight gain ,overweight and obesity.

Over weight and obesity are risk factors for cardiovascular diseases, Type 2 diabetes, Hypertension, Osteoarthritis, Dyslipidemia and Musculoskeletal problems. The increased prevalence of obesity in adults is especially concerning given that, $13 \%$ of world's adult population (11\% of men and $15 \%$ of women ) were obese in 2014.[1]

With the improvement in standard of living, decrease in physical activities, dependence of men on machine, dietary changes and other life style changes people are putting on extra weight. This gain in bodyweight and obesity is posing a real threat to health both in children and adults all over the world.

Globally the prevalence of obesity in women exceeds than men.[21]Physical function refers to a person's ability to perform basic and instrumental activities of daily living and mobility tasks. Impairments in physical function, such as the components of mobility and balance, have been linked to the development of disability.

Simple anthropometrical measurements are taken to rule out obesity and are more practical both in the clinical practice and for large scale epidemiological studies. Measurement of Body Mass Index is relatively simple and easier to calculate .Proper balance control is a key aspect of activities of daily living.[4]. Obesity is associated with serious medical complications that impair quality of life.

There are a number of studies with obese boys providing support to this association between body weight and balance stability. For obese boys aged 10-21, reported a significant negative relationship between body weight, body mass index, percentage of fat and total fat mass and a clinical balance score

Body Mass Index (BMI) is a measure of weight adjusted for height, calculated as weight in kilograms divided by the square of height in meters $(\mathrm{kg} / \mathrm{m} 2)$. Although Body Mass Index is often considered an indicator of body fatness, it is a surrogate measure of body fat because it measures excess weight rather than excess fat. Body Mass Index is a simple, inexpensive, and noninvasive surrogate measure of body fat, Factors such as age, sex, ethnicity, and muscle mass can influence the relationship between Body Mass Index and body fat. Also, Body Mass Index does not distinguish between excess fat, muscle, or bone mass, nor does it provide any indication of the distribution of fat among individuals.

Flamingo balance test is total body balance test. The single leg balance test assesses the strength of the leg, pelvic and trunk muscle as well as dynamic balance. 
Timed Up and Go test is a simple test used to assess a person's mobility and requires both static and dynamic balance .It uses the time that a person takes to rise from a chair, walk three metres, turn around walk back to the chair and sit down.

The Body Mass Index is the most common method to quantify weight across a range of body sizes in adults. Using the Body Mass Index, individuals can be classified as:

Normal Weight: BMI $18.5-24.9$

Overweight: BMI $25-29.9$

Obese: BMI $30-34.9$

Moderate Obese: BMI 35 - 39.9

Severe Obese: BMI $>40$

Studies investigating the relationship between Body Mass Index and mobility have focused on individuals with severe obesity and few studies have examined the relationship between Body Mass Index and balance. The purposes of this study were to describe how mobility and balance measures are influenced by Body Mass Index and to examine other factors that might explain the association between Body Mass Index and mobility and balance.

\section{Methodology:- STUDY DESIGN STUDY TYPE \\ SAMPLING METHOD \\ SAMPLE SIZE STUDY SETTING}

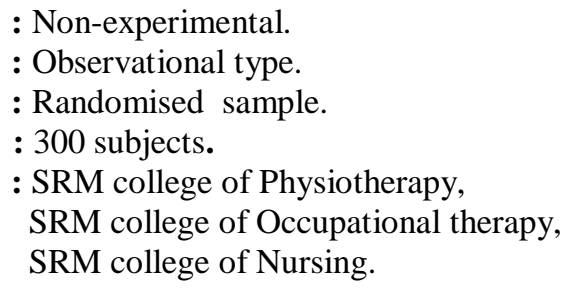

Inclusion Criteria of the study are as Follows:-

College going girls.

Age: $18-25$ years.

Girls with no specific exercise habits.

Girls who are willing to participate in the study.

Exclusion Criteria of the study are as follows:-

Beningn Paroxysmal Positional Vertigo.

Recent trauma.

Recent fractures.

Vestibular problems.

Vision problem

Any other psychological and neuromuscular disorders.

\section{Procedure:-}

College girls are approached and given with consent form. Then height and weight of these girls are measured by using the formula to calculate the Body Mass Index. After calculating the Body Mass Index of each girl they are segregated under three categories as Underweight, Normal and Overweight. Then these subjects are explained with the balance and mobility measures.

Balance is measured using Flamingo Balance Test, Where the subjects are advised to stand on the wooden beam with their dominant leg and was asked to bend the other leg and the bent leg was held by one hand and the other hand is extended forward.The measures are calculated by the number of slips/errors made by the subject for 60 seconds using a stop clock. Three repetition of the test were done and best values among three was selected.

Mobility is measured using Timed Up and Go Test, the subject is asked to sit on the chair and when "start" voice is heard they have to walk as fast as possibleand stop clock is started as soon as they start to walk, and subject has to walk till 3 meter as marked on their way. They are advisedto walk as fast as they can and should return back to the chair and stop clock is stopped then and the time is calculated. Totally three times the test was done and best of it was taken. 
Table 1:- Association Of Normal Weight Subjects With The Flamingo Balance Test And Timed Up And Go Test

\begin{tabular}{|c|c|c|c|}
\hline Group A & Mean & StdDeviation & Sig \\
\hline Normal weight & 21.3633 & 1.78894 & \multirow[t]{2}{*}{0.155} \\
\hline Flamingo Balance test & 8.27 & 2.77381 & \\
\hline Normal weight & 21.3633 & 1.78894 & \multirow[t]{2}{*}{.062} \\
\hline TUG test & 4.9200 & 0.61431 & \\
\hline
\end{tabular}

$\mathrm{p}>0.05$

This table shows that there is no statistically significant association betweennormal weight subjects with the Flamingo Balance Test and Timed Up and Go Test

\section{Graph 1:-}

CORRELATION BETWEEN BMI AND FLAMINGO BALANCE TEST IN NORMAL WEIGHT

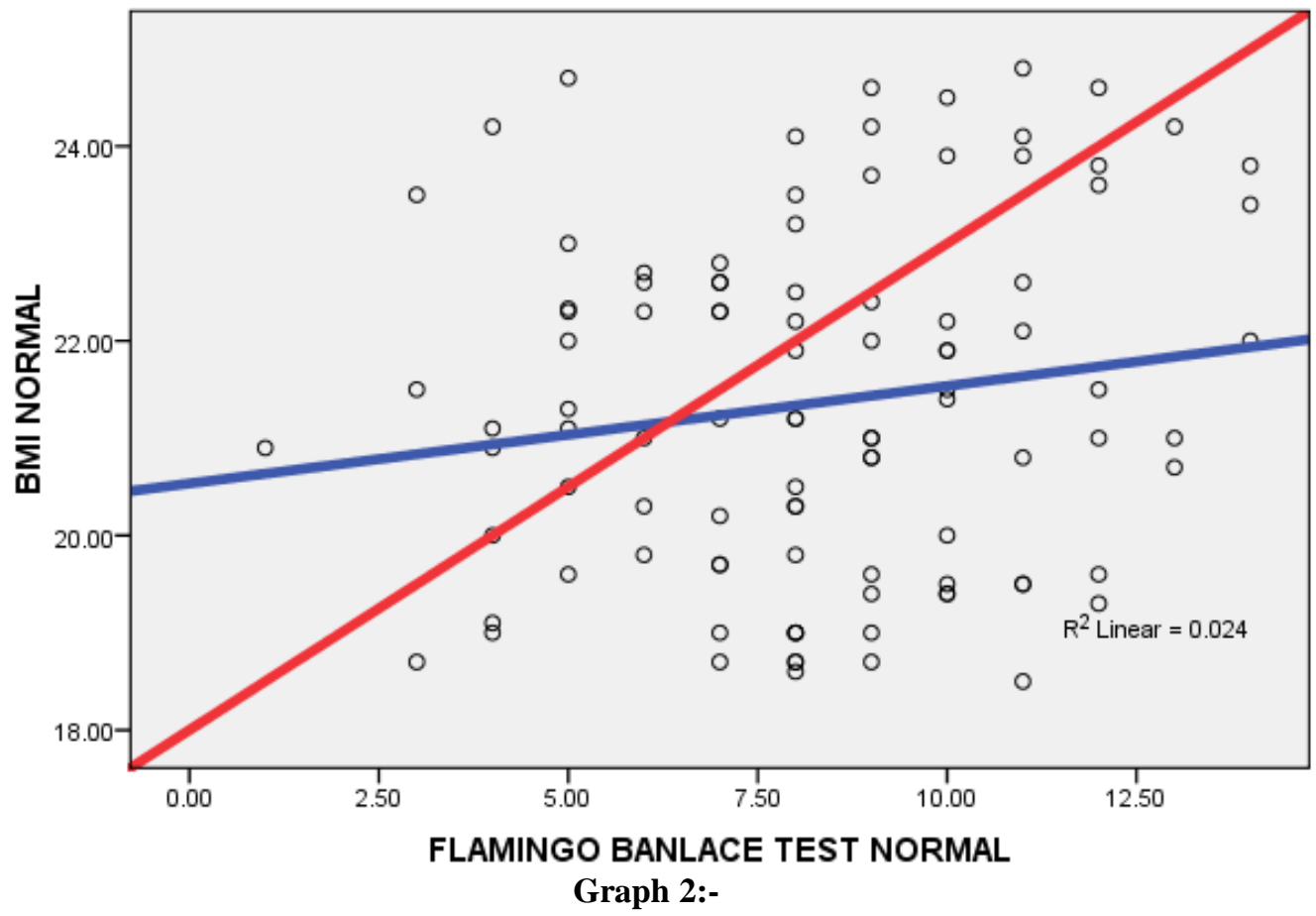


CORRELATION BETWEEN BMI AND TUG TEST IN NORMAL WEIGHT

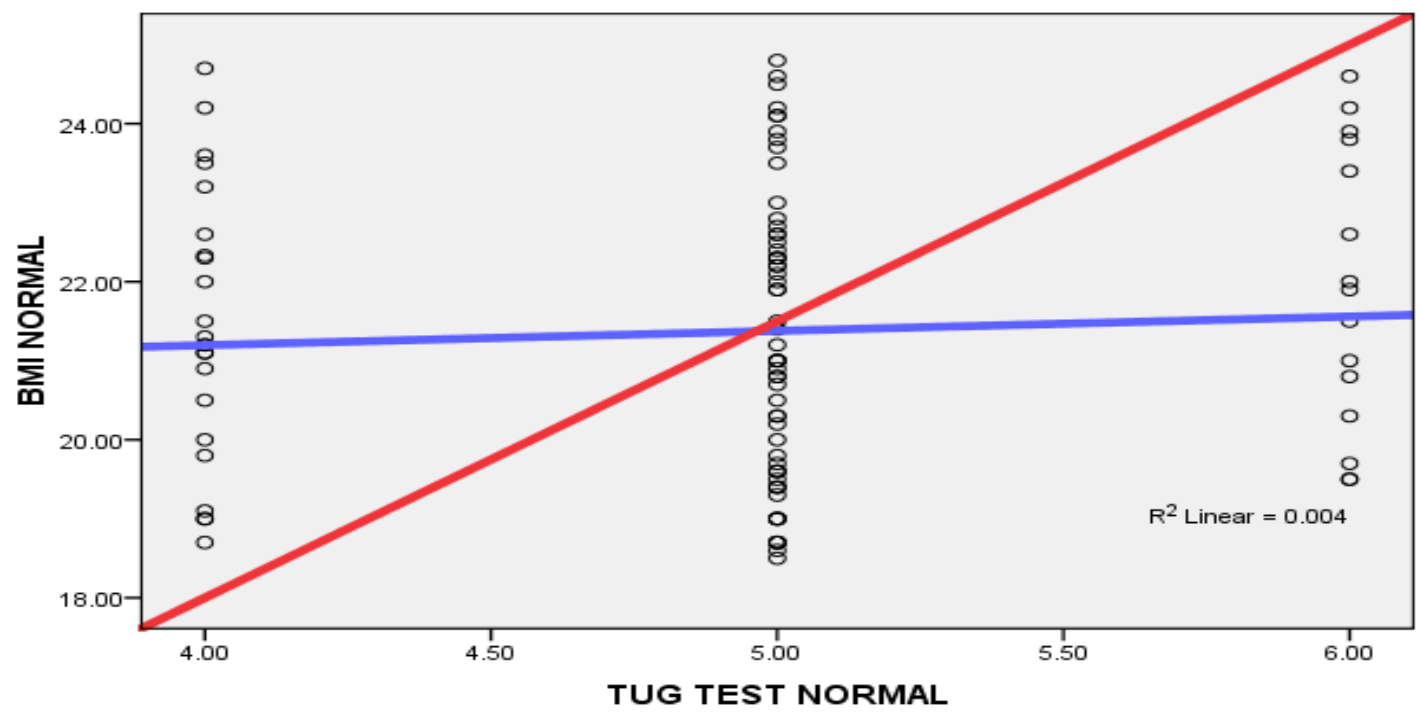

Graph 3:- Correlation Between Flamingo Balance Test And Timed Up And Go Test In Normal Subjects

\section{NORMAL SUBJECTS CHART REVIEW}

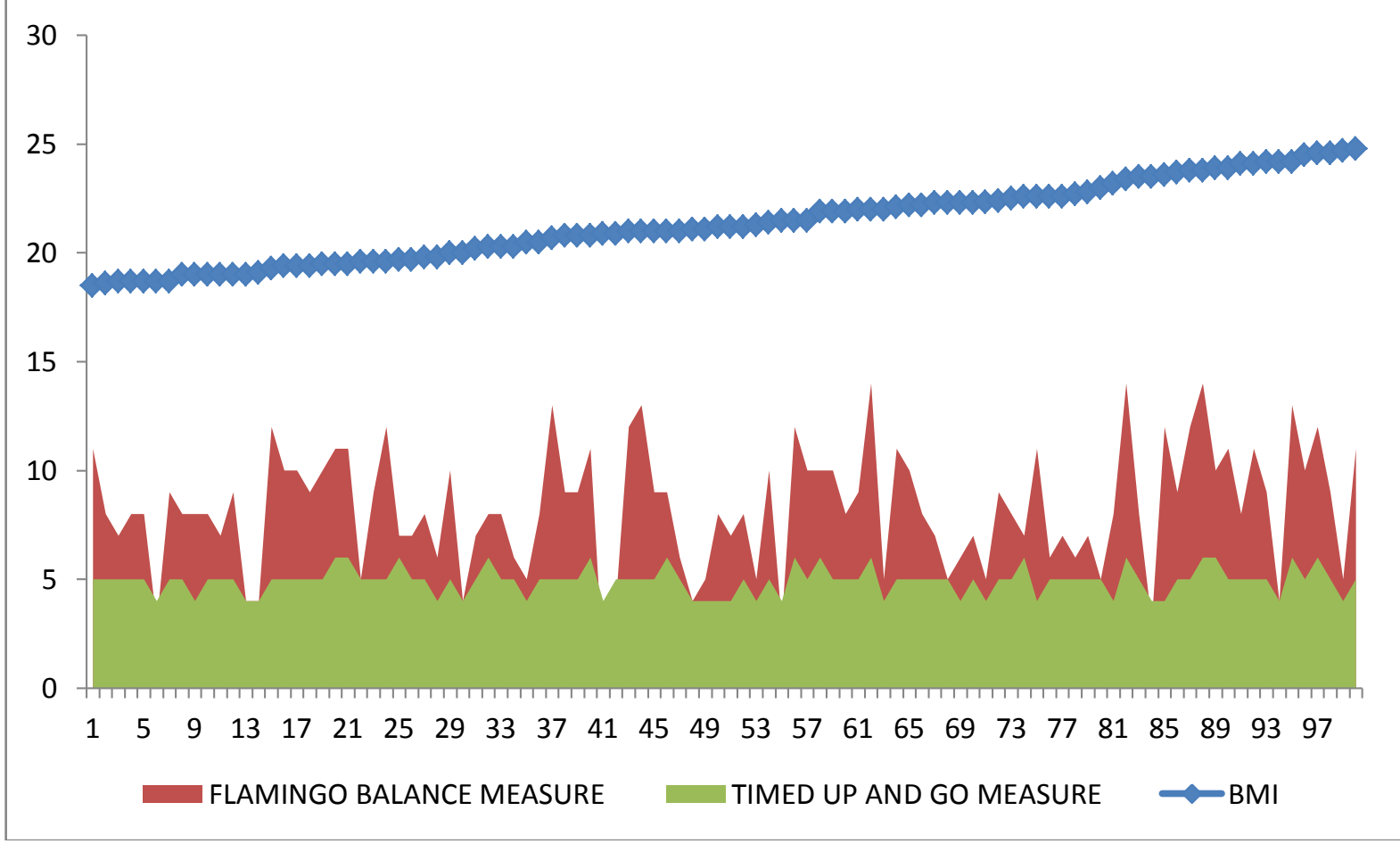

Table 2:- Association Of Underweight Subjects With The Flamingo Balance Test And Timed Up And Go Test

\begin{tabular}{|c|c|c|c|}
\hline Group B & Mean & StdDeviation & Sig \\
\hline Under weight & 17.2556 & 1.04591 & 0.176 \\
\hline Flamingo Balance test & 8.8800 & 2.51171 & \\
\hline Under weight & 17.2556 & 1.04591 & 0.105 \\
\hline TUG test & 5.1600 & 0.56354 & \\
\hline
\end{tabular}


$\mathrm{p}<0.05, \mathrm{p}>0.05$

This table shows that there is statistically significant association between Under Weight Subjects With The Flamingo Balance Test and no statistically significant association were found between Under Weight Subjects and Timed Up And Go Test.

Graph 4:-

CORRELATION BETWEEN BMI AND FLAMINGO BALANCE TEST

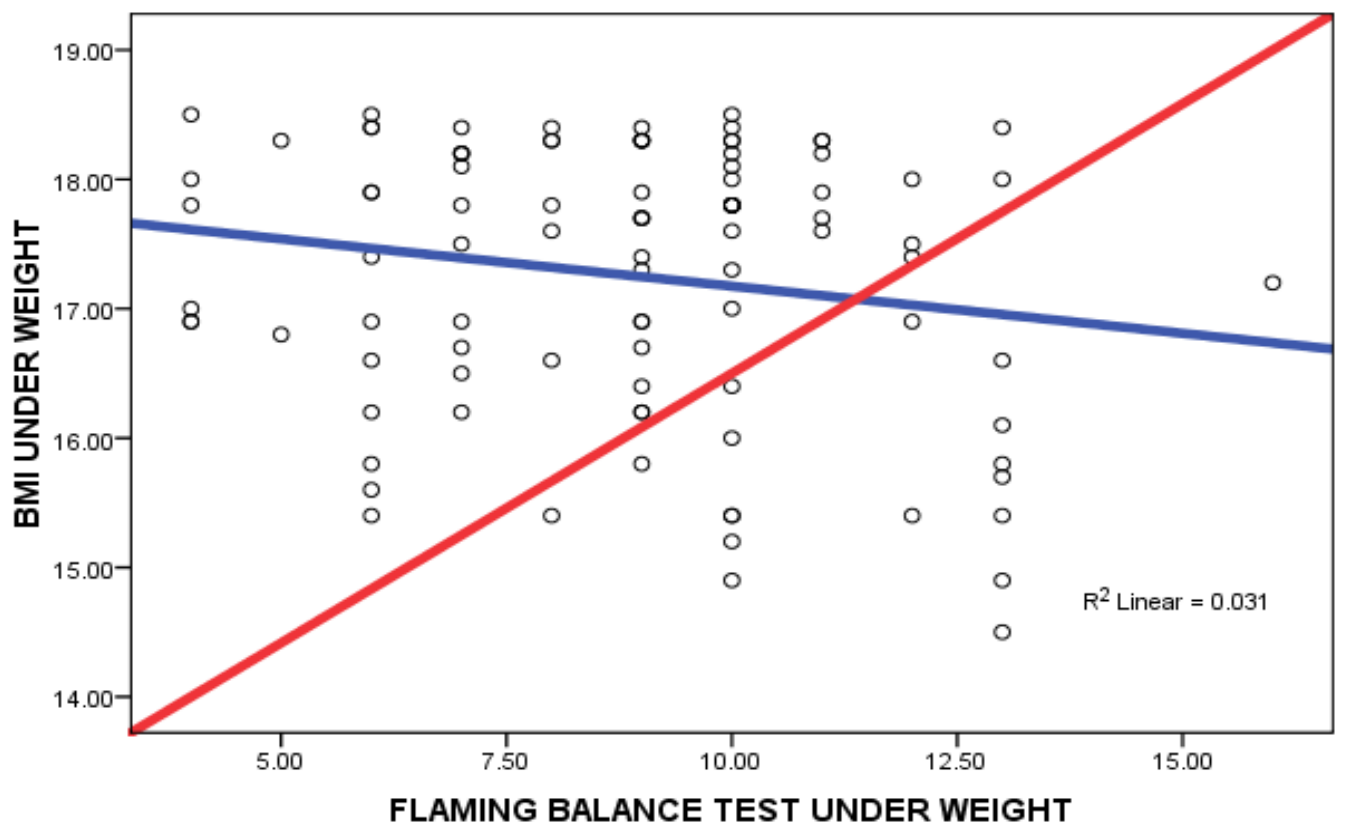

Graph 5:-

CORRELATION BETWEEN BM UNDER I AND TUG TEST IN UNDER WEIGHT

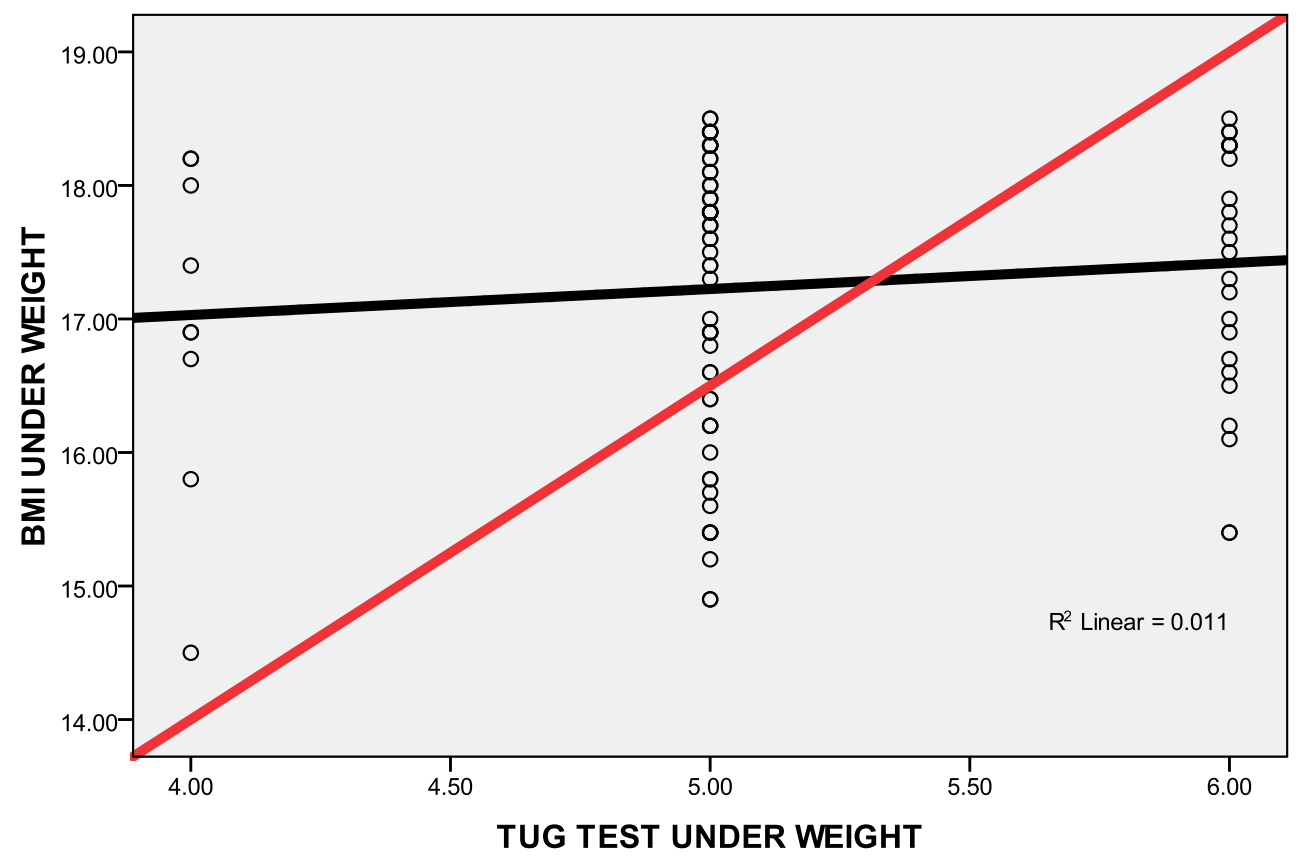


Graph 6:- Correlation Between Flamingo Balance Test And Timed Up And Go Test In Under Weight Subjects.

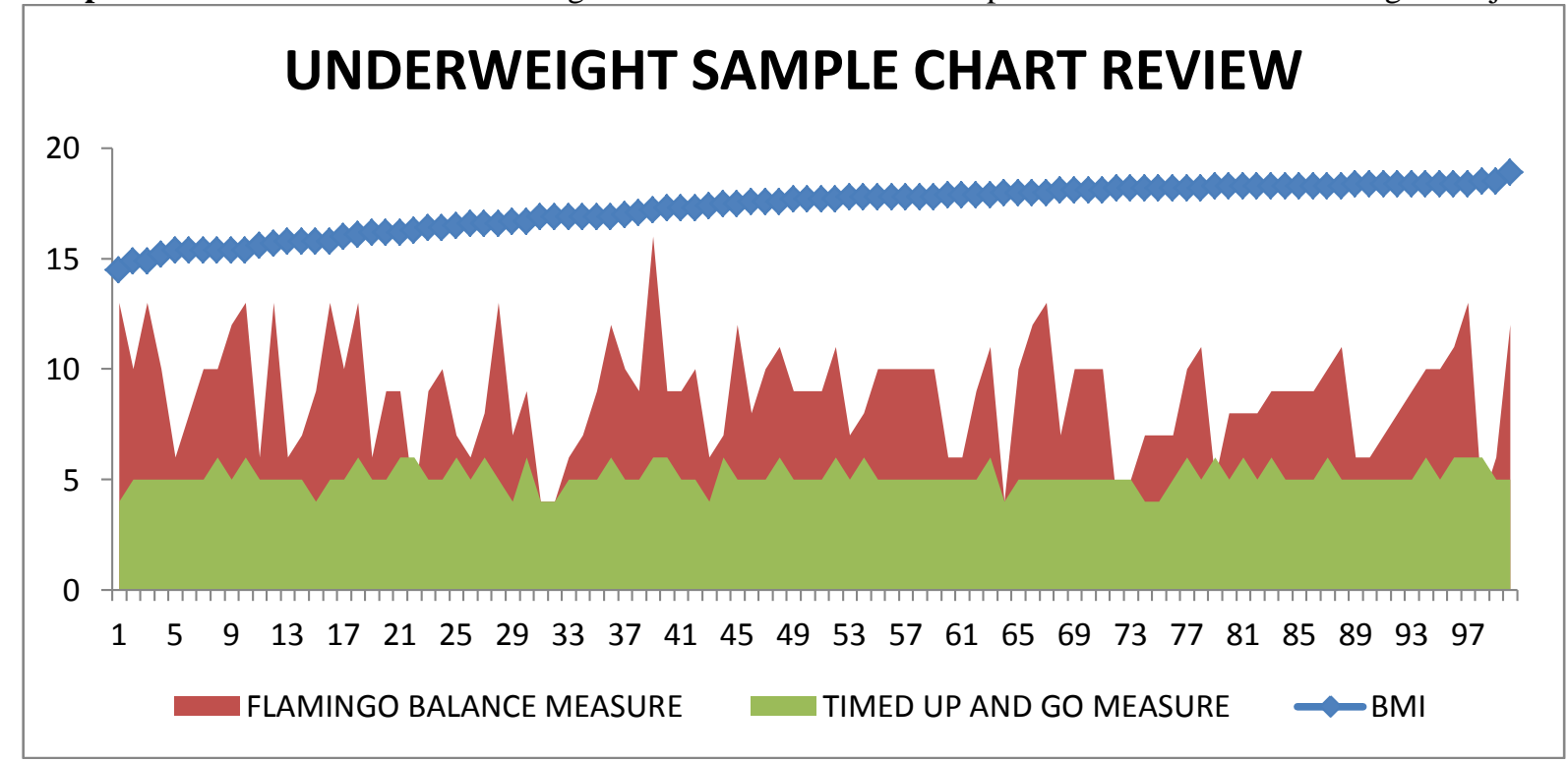

Table 3:- Association Of Overweight Subjects With The Flamingo Balance Test And Timed Up And Go Test

\begin{tabular}{|c|c|c|c|}
\hline Group C & Mean & StdDeviation & Sig \\
\hline Over weight & 27.0224 & 1.85385 & 0.262 \\
\hline Flamingo Balance test & 9.3960 & 2.20490 & \\
\hline Over weight & 27.0224 & 1.85385 & 0.158 \\
\hline TUG test & 5.2970 & 0.50089 & \\
\hline
\end{tabular}

$\mathrm{P}<0.05 \mathrm{p}>0.05$

This table shows that there exist a statistically significant association between OverWeight Subjects With The

Flamingo Balance Test whereas no statistically significant association was found between Overweight subjects and Timed Up And Go Test.

\section{Graph 7:-}

CORRELATION BETWEEN BMI AND FLAMINGO BALANCE TEST IN OVER WEIGHT

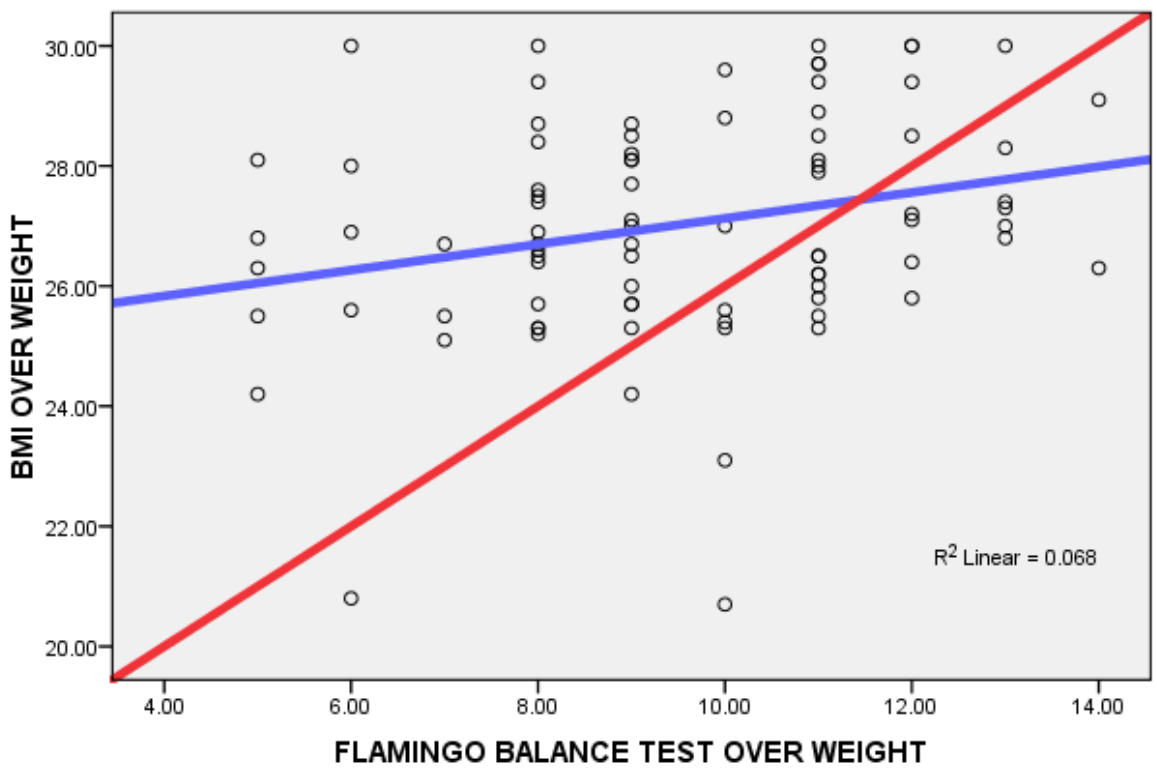




\section{Graph 8:-}

CORRELATION BETWEEN BMI AND TUG TEST IN OVER WEIGHT

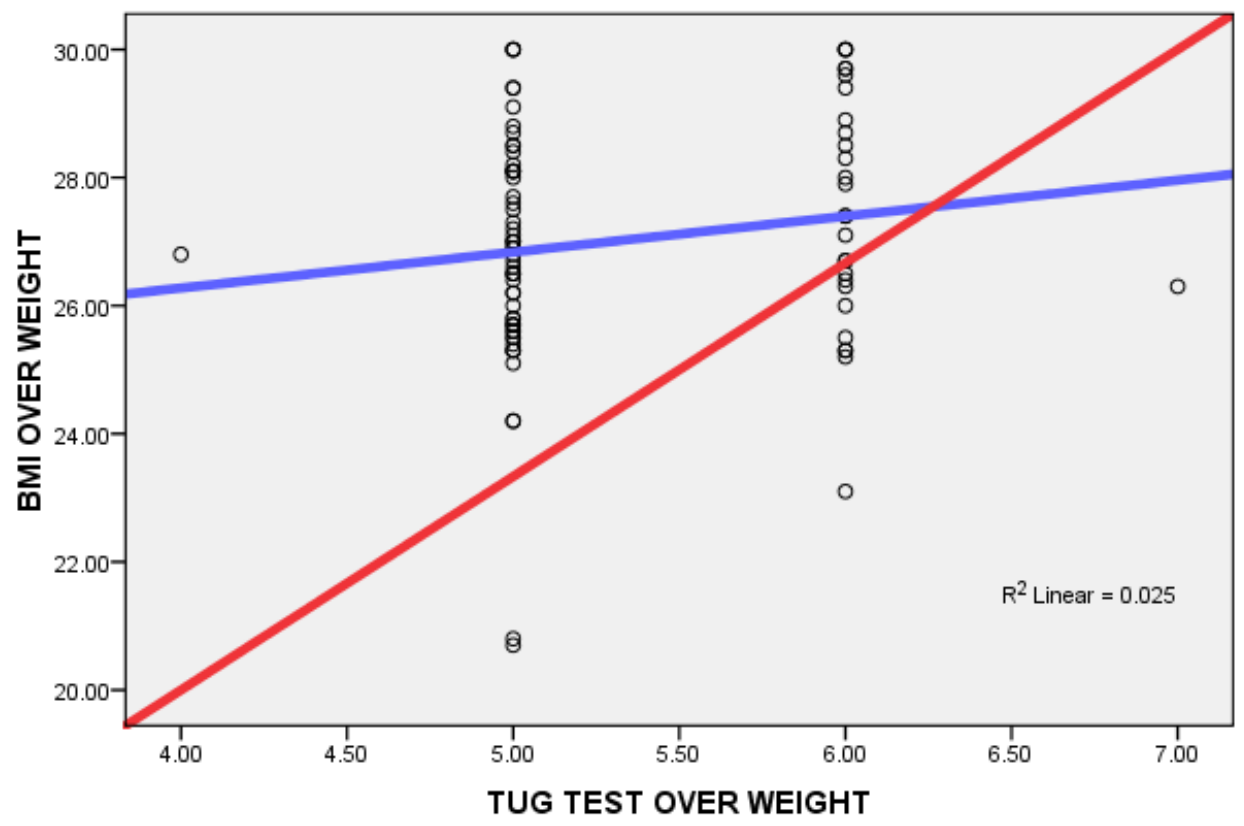

Graph 9:- Correlation Between Flamingo Balance Test And Timed Up And Go Test I Over Weight Subjects.

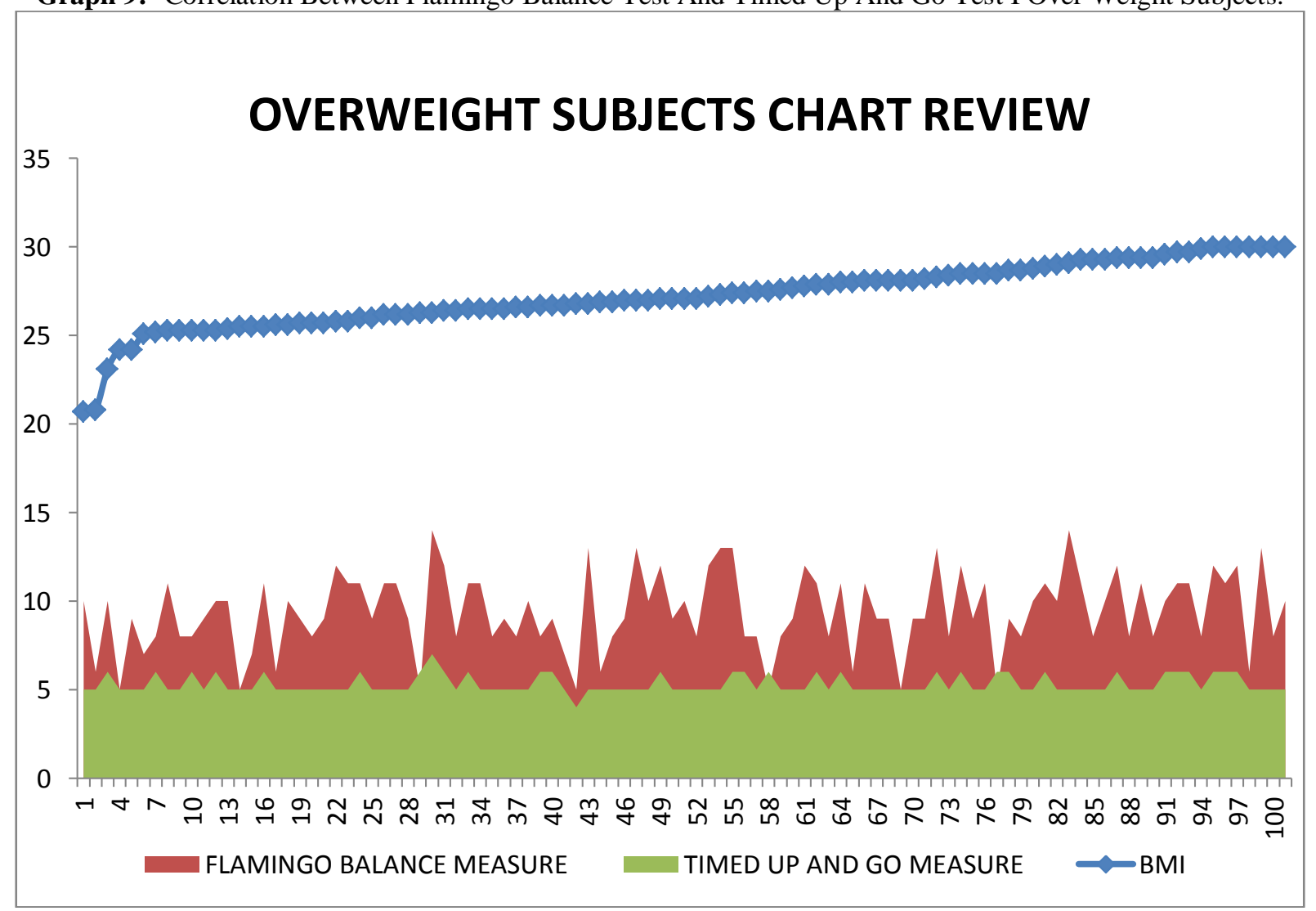




\section{Results:-}

Results of the study showed that the underweight and overweight subjects show more difference in the balance test compared with the mobility test conducted.as there was less number of obese samples and those subjects were excluded from the study and if they were included in the study there may be significant result in mobility also..

\section{Discussion:-}

Although not much data is available on over weight / obesity in adolescent, but there is growing concern about these problems. The 1988-91 NHANES cycle III study identified $21 \%$ of adolescents with 12-19 years of age as being over weight. 18 Currently $35 \%$ of American college students are now over weight.

The prevalence of over weight and obesity in Indian school based data demonstrates an obesity range of 5.6\% to $24 \%$ for the children and adolescents respectively. WHO estimates that globally $60 \%$ of deaths are due to unhealthy diets and physical inactivity, with $79 \%$ of these deaths in developing countries culture.

The purpose of the study is to find the association of Body Mass Index with balance and mobility measures on college girls.

Simple balance task related to everyday activities were selected.

Flamingo balance test

Timed up and go test

Flamingo balance test is a total body balance test used to assist the strength of leg, pelvic, trunk muscles as well as the dynamic balance.

Timed up and go test is a simple test used to asses person mobility and requires both static and dynamic balance.

When examining balance and mobility across weight groups in younger adults, there were more differences in balance than in mobility. Individuals who were classified as being of normal weight found no association with the balance ( $>>0.05$ )and those subjects classified as Underweight and Overweight were found to have impaired balance as assessed with Flamingo Balance test $(\mathrm{p}<0.05)$.

This goes in hand with Abed Parseh.et.al.,(2015) Who stated that there is an inverse relationship between BMI and the balance.

Singh, D., Park, W., Levy, M. S., \& Jung, E. S. (2009) suggested that obesity may impair postural control and may be a risk factor of balance loss and falls, especially during prolonged physical work activities during prolonged quiet standing.

This can be explained by that Obesity significantly changes the way the body moves by causing changes in anthropometry. Increased body weight and mass modify how the limbs and whole body create and react to forces . Excess adiposity also interferes with the interaction of joints and muscles that are crucial to functional capacity and postural balance.

Chambers et al. examined the effects of obesity on body segment anthropometry in the obese geriatric population and observed that body mass distribution varied with both obesity and gender. Normal weight males had greater trunk and upper extremity segment mass as compared to women. However, obese elderly individuals showed a significantly greater trunk segment mass, regardless of gender. This is representative of the increased abdominal fat that is correlated to higher Body Mass Index .

The propensity toward increased abdominal fatness contributes to the anterior shift of the body's Centre of mass. This modification is particularly consequential as an anterior displacement of the Centre Of Mass significantly increases the magnitude of ankle torque required to stabilize the body in the upright stance. An anterior shift in whole body Centre Of Motion also threatens stability by placing the line of gravity closer to the boundary of the body's Base of support. 
Range of motion (ROM) is also an important facet of functional movement . Capacity of joint Range Of Motion in the trunk and lower limbs may influence the ability to maintain and recover balance, especially as the amplitude of perturbation increases. This is especially relevant in the obese, for whom recovery from perturbations of large amplitude may present the most significant balance challenge .

Regarding mobility no association exist between Normal weight,Under weight and Overweight subjects and Timed Up and Go test. $(\mathrm{p}<0.05)$.

Madhuri Gaur, Kunjal Parekh.(2015) who concluded that Higher BMI levels are associated with poorer mobility and balance.

This can be explained with that mobility is not affected in this study, one reason may be that of young age limits (18-25 years) so that they find less difficulty to move. Personal factors include sex, age, and past and current experience and for the purpose of this review will be considered in terms of their influence on how mobility disability is experienced by the individual. Age has been identified as a factor that contributes to mobility disability however, as previously mentioned, obesity early in life leads to an increased risk of mobility disability later in life. It has been suggested that maintaining a stable weight in older adults could be important in preventing functional mobility limitations.39 Results of studies of obese elderly populations show no differences in the functional mobility (moving from sitting to standing) compared to healthy weight elderly counterparts.

A greater number of individuals with moderate obesity were unable to complete the performance-based measures of balance compared with those who were of normal weight.It also modifies body geometry, increases the mass of the different segments and imposes functional limitations pertaining to the biomechanics of activities of daily living that may predispose the obese to injury.

Lack of completion of balance measures in participants with higher Body Mass Index was related to inability to assume the test positions(flamingo balance test). Thus, had all participants with obesity been able to participate the balance measures, the results might have differed. Poor motor function leads to poor performance on tasks. This could be a detriment to adaptation because adaptive behavior involves tailoring actions to variations in one's environment.

Therefore motor plans need to be changed during motor actions [14]. In the obese population, poor motor planning and an inability to adapt motor plans during the course of action could lead to more frequent losses of balance or the inability to recover from unavoidable losses of balance.

The change in diet and physical activity contribute to the increased prevalence of obesity in youth. Dietary pattern in adolescence not only influence their immediate well being but also have an impact on their long term health. Some of these behaviors may be compromised in adolescents because they are less dependent on their parents for meals, spend more time away from home and consume greater quantity of fast foods and snacks.

In the current study it was observed that many participants were in the habit of consuming junk food in the form of samosa, patties, hot dogs, chocolates, pastries, cold drinks and chips etc. Junk food is basically a slang term used for food with high calories and limited nutritional values.

In addition to impairments of the musculoskeletal system those patients with obesity may also have cognitive impairments that could interfere with motor planning and therefore also contribute to mobility disability. The age of the patient, distribution of body fat, and factors in the environment in which the person plans to be physically active must also be considered.

Weight loss programs should include the adoption of resistance exercise and regular physical activity. Individuals with obesity were less likely to engage in physical activity compared with those who were overweight and those of normal weight.

Young adults with obesity should be routinely advised by their health care provider to become more physically active for the purpose of losing weight and reducing cardiovascular and metabolic risk profiles. Although such 
advice is well intended to promote health and wellness, changes to physical activity levels and the associated benefits are illusive unless issues related to functional mobility are addressed.

Thus to conclude it is emphasised that adolescence is a unique intervention point in the life cycle and the knowledge regarding optimal nutrition can be acquired during this period that could prevent or delay adult-onset diet related illnesses later on. Further, it is during adolescent years that most people develop life style habits that are likely to become the foundations of their adult behaviours.

The ability to move without falling is also essential for daily life functions. This study demonstrates that when categorized by Body Mass Index levels, underweight and overweight displayed lower capacity on balance skills when compared with the normal subjects., whereas, no significant difference foe mobility measures on either groups. The lack of differences may also be due to the young age group and the moderate degree of obesity.

\section{Conclusion:-}

This study was focused to find the association of Body Mass Index with balance and mobility measures among college girls. This study concludes that when categorised by Body Mass Index levels, underweight and overweight displayed lower capacity on balance skills when compared with the normal subjects., whereas, no significant difference foe mobility measures on either groups. The lack of differences may also be due to the young age group and the moderate degree of obesity

\section{References:-}

1. .LaCroix AZ, Guralnik JM, Berkman LF, et al. Maintaining mobility in late life; II: smoking, alcohol consumption, physical activity, and body mass index. Am J Epidemiol. 1993

2. Guralnik JM, Simonsick EM, Ferrucci L, Glynn RJ, Berkman LF, et al. (1994) A short performance battery assessing lower extremity function: association with self-reported disability and prediction of mortality and nursing home admission.

3. Han T. van Leer E, Seidell J, Lean M. Waist cicumference action levels in the identification of cardiovascular risk factors: prevalence study in a random sample. BMJ 1995

4. Coldiz G, willett W, Rotnitzky A, Manson 1. Weight gain as a risk factor for clinical diabetes mellitus in women. Ann Intern Med 1995

5. Wolpert DM \&Miall RC. Forward models for physiological motor control. Neural Networks 1996

6. World Health Organization. Obesitypreventing and managing the Global Epidemic: SReport of a WHO cosultation on obesity. Geneva: World Health Organization, 1998.

7. Han TS ,Tijhuis MA ,Lean Me ,Seidell JC ,AM J public health.1998 Quality of life in relation to overweight and body fat distribution

8. Launer L, Harris T, Rumpel C, MadansJ.. Body mass index, weight change, and risk of mobility disability in middle-aged and older women.,2000

9. Ben McGraw, Bruce A. McClenaghan, Harriet G. Williams, John Dickerson, Dianne S. Ward concluded that Gait and postural stability in obese and nonobeseprepubertal boys Archives of Physical Medicine and Rehabilitation, Volume 81, Issue 4, April 2000,

10. Ho SC, Chen YM, Woo JL, Leung SS, Lam TH, Janus ED. Association between simple anthropometric indices and cardiovascular risk factors, IntObesRelatMetabDisord 2001

11. Yadav S. Obesity: An increasing problem in the developing countries. Indian J Practical Pediatr 2001

12. Rossner S (2002) Obesity: the disease of the twenty-first century. Int J ObesRelatMetabDisord26 .

13. Welborn TA, Dhaliwal SS, Bennett SA. Waist-hip ratio is the dominant risk factor predicting cardiovascular death in Australia. Medical Journal of Australia 2003

14. Yusuf S, Hawken S, Ounpuu S. Effects of potentially modifiable risk factors associated with myocardial infarction in 52 countries (the INTERHEART study): case-control study. Lancet 2004

15. Rissanen A, Heliovaara M, Knekt P, Reunanen A, Aromaa A, Maatela J .Risk of disability and mortality due to overweight in a Finnish population.2004

16. Mendez MA,Monterio CA, PopkinBM,Am J Clin Nutr.2005. overweight exceeds underweight among women in most developing countries.

17. Yusuf S, Hawken S, Ounpuu S, Bautista L, Franzosi MJ and Commerford P. Obesity and the risk of myocardial infarction in 27000 participantstrom 52 countries: a case-control study. Lancet 2005 
18. Wearing SC, Hennig EM, Byrne NM et al. The biomechanics of restricted movement in adult obesity. Obesity Reviews 2006;

19. Browning RC, Baker EA, Herron JA, Kram R, J Appl Physiool.2006 .Effects of obesity and sex on the energetic cost and preferred speed of walking

20. Hue O, SimoneauM,MarcotteJ,BerriganF,Dore J, Marceau P, Tremblay A, Marceau S, Teasdale N. Gait Posture 2007. Body weight is a strong predictor of postural stability. 